\title{
Assessment of safety in drinking water supply system of Birjand city using World Health Organization's water safety plan
}

\author{
Akbar Eslami ${ }^{1}$, Mohtasham Ghaffari ${ }^{2}$, Behnam Barikbin $^{3}$, Farzaneh Fanaei $^{{ }^{*}}$ \\ ${ }^{1}$ Environmental and Occupational Hazards Control Research Center, Shahid Beheshti University of Medical Sciences, Tehran, Iran \\ ${ }^{2}$ Department of Education and Health, School of Public Health, Shahid Beheshti University of Medical Sciences, Tehran, Iran \\ ${ }^{3}$ Department of Environmental Health Engineering, School of Public Health, Birjand University of Medical Sciences, Birjand, Iran \\ ${ }^{4}$ Department of Environmental Health Engineering, School of Public Health, Shahid Beheshti University of Medical Sciences, Tehran, \\ Iran
}

\begin{abstract}
Background: The conventional method for managing drinking water quality is not a suitable preventive strategy for protecting public health. A water safety plan (WSP) presents a systematic approach to ensuring the health and quality of drinking water. This study assessed the drinking water supply system safety of Birjand city using the WHO's WSP.

Methods: This investigation employed the WSP-QA Tool and the WSP manual of the WHO and the AWI. For this purpose, software checklists were prepared and, after confirmation of content and face validity, completed based on Birjand's water and wastewater company records and interview with company's experts. Data was analyzed using WSP-QA Tool.

Results: From total possible 440 points for full use of the program and 328 points of the studied phases, a score of 190 was acquired, indicating a $43.18 \%$ coordinated implementation with WSP. System description and management procedures showed the maximum and minimum percentages of congruency with the WSP of $87.5 \%$ and $25 \%$, respectively. Among the components of the water supply system, water resource had the most attention

Conclusion: As regards the percentage of overall WSP-phase implementation and the low attention given to some key parameters of the water supply system, such as risk assessment and management procedures, the system currently enjoys a relatively medium level of safety. However, the high points of some phases such as system description, operational monitoring and verification enhance the system's flexibility for changing the current approach of qualitative management to the WSP.

Keywords: Drinking water, Safety, Water supply, Risk assessment, Software

Citation: Eslami A, Ghaffari M, Barikbin B, Fanaei F. Assessment of safety in drinking water supply system of Birjand city using World Health Organization's water safety plan. Environmental Health Engineering and Management Journal 2018; 5(1): 39-47. doi: 10.15171/EHEM.2018.06.
\end{abstract}

Article History:

Received: 19 August 2017

Accepted: 7 November 2017

ePublished: 10 December 2017

\section{Introduction}

Possessing water with a suitable quality and quantity is considered the basis for the development of sustainable health for any society $(1,2)$. The water supply system has a wide extension requires special control considering the status and relationship of the system with the surrounding environment, the contamination potential resulting from this relationship and, in turn, threats to consumer health. Thus, this issue is of great interest to many researchers and authorities (3). Based on current estimations, one-sixth of the world's population has absolutely no access to healthy water within a distance of $1 \mathrm{~km}$ from their living place. Furthermore, one-fifth of the population has absolutely no suitable way to discharge waste (4). Water resources are always subject to contamination and reduction of quality because of indiscriminate exploitation, and this can adversely affect the health of society (5). For this reason, supplying adequate, quality drinking water to urban areas has always been an important challenge facing managers and decision-makers. Various parts of urban water systems are always menaced by different natural, non-natural, and functional threats which may irrecoverably affect the quantitative and qualitative reliability of the water supplied to consumers (6). Accordingly, the provision, transfer, and distribution systems of urban water are considered principal infrastructures in any society that are directly associated with the vital and primary needs of people (7). Despite all attempts to provide healthy drinking water, waterborne diseases are considered a serious health concern around the world. Digestive diseases 
that originate from contaminated water and deficient health measures are the reason of 2.4 million deaths and 73 million disabilities (8). Epidemic diseases resulting from unhealthy water resources affect all countries, whether developed or developing, and cause mortality and economic damage to individual people and society as a whole (9). In its newest report associated with world health statistics (WHO 2011), the WHO has introduced unsafe drinking water (along with eight other parameters) as a preventive risk factor causing disease and mortality around the world. Despite international attention to the issue of water, waterborne diseases still remain a major health concern in the world. However, around one-tenth of the load of global diseases can be prevented by improving water resources and their management (10). Drinking water safety management is changing into an integrated risk management and assessment approach. This approach encompasses all stages and processes involved in the provision of drinking water from catchment to the consumer, and it is of interest to evaluate drinking water safety in water supply systems (11). Traditionally, drinking water quality management is based on final point tests, and comprehensive attention is not paid to risk management or the assessment process. Therefore, it is not a suitable preventive strategy for protecting public health (12). Accordingly, the development of strategies for managing the quality of water resources in Iran is an important measure for policymakers in the water sector, and its most important elements will be preserving the quality of resources for drinking water from production to consumption (13). A major global transformation in the management of water resources around the world dates back to when the third qualitative guidelines of drinking water (WHO) and the charter of safe drinking water (Bonn Charter, 2004) were published in 2004. At that time, WHO and the International Water Association (IWA) both supported running a process called the water safety plan (WSP) $(14,15)$. The best justification for this solution lay in the fact that delivering healthy water is not merely dependent on achieving a high final quality level of treated water. Rather, water supply systems may fulfill this aim while having hidden design or operation defects that could cause different incidents, including the risk of uncontrolled contaminants in the catchment, incomplete design of the treatment process, leakage in water supply systems, or improper operational methods (15). The WSP is a powerful tool for managing the quality of drinking water: a systematic approach to ensure the quality of water delivered to consumers from catchment to consumption. It also regulates step-by-step preventions for risk management regarding water contamination (1618). This system is in charge of detecting and monitoring special risks (microbial, chemical, and physical) which have the potential to inflict damaging effects on the health of products. In this way, it is ensured that the water of interest is in line with health-based objectives. In 2009, the WHO and the IWA presented the WSP practical guidelines comprised of 11 consecutive executive steps. These guidelines state the way WSP should be developed and implemented for drinking water supply systems (1). The major steps of this plan are summarized in Table 1. Uganda was the first country in Africa to use the WSP with the aim of fulfilling its national standards without employing further treatment stages (19). Since 2008, Vietnam has been employing the WSP for its urban water supply systems and has cited the advantages of improved drinking water quality, increased consumer satisfaction, decreased number of cases of waterborne disease, ensured continual provision of water, and the purposefulness of investments (20). The WSP workshop in Berlin in 2014 also introduced this plan as an effective method for risk management in the 21th century. It stated that, even in the case of high correspondence with the European Union Drinking Water Directive (EU-DWD), the WSP is a systematic method and useful managerial tool to guarantee continuous delivery of healthy drinking water to consumers (21). In 2005, 10 Latin American countries emphasized the implementation of the WSP of interest to the WHO. Following them, the Pan American Health Organization (PAHO), the Centers for Disease Control and Prevention (CDC), and the Environmental Protection Agency (EPA) employed the WSP in Jamaica in 2006 (22). In 2010, the WHO and the IWA presented the WSP quality assurance (WSA-QA) tool software to evaluate stages of the WSP. It seems that the novelty of this software prevented its application in qualitative management of drinking water across different countries of the world from becoming prevalent, even in countries which have the experience of evaluation and application of the WSP. This plan is indeed a tool which can detect the strong and weak points in the implementation of every single stage of WSP so as to consolidate the benefits gained from its implementation. One of the characteristics of this software is its capability to be used as a guide where WSP has not been comprehensively implemented or is in the primary stages of implementation. In the present study, this feature has been taken into consideration $(14,23)$.

\section{Characteristics of the studied area}

This descriptive-analytical study was conducted on the water supply system of Birjand city, located in southern Khorasan province, Iran in 2015. Birjand city, with an area of $5400 \mathrm{~km}^{2}$ covering a geographical position from $58^{\circ} 4^{\prime \prime} 0^{\prime}$ to $59^{\circ} 40^{\prime \prime} 0^{\prime} \mathrm{E}$ and from $32^{\circ} 40^{\prime \prime} 0^{\prime}$ to $33^{\circ} 40^{\prime \prime} 0^{\prime} \mathrm{N}$, is the capital city of southern Khorasan located in eastern Iran (24-26) (Figure 1). According to the Studies of Water and Wastewater Company of Birjand, this city is fully dependent for its drinking water on groundwater accessed through 32 deep wells with a capacity of around $800 \mathrm{~L} / \mathrm{s}$, located in different plains, including Sarbisheh, Marak, Aliabad, and Rekat. Water is supplied through transfer lines $150 \mathrm{~km}$ long and three pumping stations, 
Table 1. Description of executive stages of water safety plan in water supply systems (1)

\begin{tabular}{|c|c|}
\hline Stage & Stage description \\
\hline $\begin{array}{l}\text { Development of WSP } \\
\text { team }\end{array}$ & $\begin{array}{l}\text { An expert qualified team with sufficient experience and expertise for the extraction, treatment, and distribution of water } \\
\text { and familiarity with the risks that can be posed to water safety from catchment to consumption is developed. }\end{array}$ \\
\hline $\begin{array}{l}\text { Water supply system } \\
\text { description }\end{array}$ & $\begin{array}{l}\text { The water supply system is investigated across the four stages of catchment, treatment plant, distribution system, } \\
\text { and consumption point, which allows for the adequate management and assessment of risks with the aim of ensuring } \\
\text { documentation of raw water quality. }\end{array}$ \\
\hline $\begin{array}{l}\text { Hazard identification } \\
\text { and risk assessment }\end{array}$ & $\begin{array}{l}\text { Hazards (physical, chemical, and biological) and hazardous events in water catchment, treatment plant, reservoirs, } \\
\text { distribution system, and consumption points are identified; risk is assessed based on documentation available in the water } \\
\text { catchment, treatment plant, reservoirs, distribution system, and consumption points. }\end{array}$ \\
\hline $\begin{array}{l}\text { Control measures and } \\
\text { validation }\end{array}$ & $\begin{array}{l}\text { Concurrent with hazard identification and risk assessment, the WSP team should deal with potential and existing control } \\
\text { criteria. This can be done by field observations, the properties of the produced water, or data monitoring. The scope of risk } \\
\text { reduction by each control criterion will specify the extent of its effectiveness. }\end{array}$ \\
\hline $\begin{array}{l}\text { Development of } \\
\text { improvement plan }\end{array}$ & $\begin{array}{l}\text { If an important risk associated with water safety is detected in the previous stage and it is proven that the current controls } \\
\text { are not effective or are essentially absent, then a short-, mid-, and/or long-term improvement plan should be implemented. }\end{array}$ \\
\hline Operational monitoring & $\begin{array}{l}\text { Operational monitoring includes consecutive and planned observations and measurements to prove continuity of effective } \\
\text { performance of the control criteria. Monitoring control points is essential to supporting risk management. }\end{array}$ \\
\hline $\begin{array}{l}\text { Verification the } \\
\text { efficiency of WSP }\end{array}$ & $\begin{array}{l}\text { Verification through activities such as internal and external audits on operational activities and investigation of satisfaction } \\
\text { of consumers ensure that the design and operation of the system have the potential for continuous delivery of water with } \\
\text { a special quality to fulfill health-oriented objectives. }\end{array}$ \\
\hline $\begin{array}{l}\text { Management } \\
\text { procedures }\end{array}$ & $\begin{array}{l}\text { Management includes standard operating procedures which are essential components of the WSP under typical } \\
\text { operational conditions and at the incidence of accidents. The procedures should be developed by experienced employees } \\
\text { and, if necessary, they should be updated with consideration given the implementation of an improvement plan and } \\
\text { reviews of accidents. }\end{array}$ \\
\hline $\begin{array}{l}\text { Development of } \\
\text { supporting programs }\end{array}$ & $\begin{array}{l}\text { Supporting programs are activities that deal with supporting issues such as the development of knowledge and human } \\
\text { skills, commitment to the WSP, and enhancement of the ability of management systems to deliver safe water. }\end{array}$ \\
\hline $\begin{array}{l}\text { Review of WSP } \\
\text { following an incident }\end{array}$ & $\begin{array}{l}\text { To ensure that new risks are regularly reviewed, the WSP should be reevaluated after any emergency or accident which } \\
\text { threatens the provision and distribution of safe water. }\end{array}$ \\
\hline Periodic review of WSP & $\begin{array}{l}\text { The WSP group should deal with the development of a general, periodical review of the plan and be informed about gained } \\
\text { experiences and new procedures. }\end{array}$ \\
\hline
\end{tabular}

interstitial pressure tanks, and collection reservoirs. After passing through the treatment plant, the water then enters five water storage reservoirs with a capacity of $35000 \mathrm{~m}^{3}$. Following chlorination, it is finally delivered to citizens through a water supply system $560 \mathrm{~km}$ long with 68000 branches. By the time it reaches the consumption point, $26 \%$ of the water extracted from these resources is not considered as water or water loss leaving the consumption cycle (27). The current study analyzed the qualitative control process and provision of drinking water in the water supply system of Birjand city based on the WSP guidelines (WHO, 2009) using the WSPQA TOOL. It was expected that this investigation would highlight the necessity of changing the current approach by identifying preventable and weak points in the water quality management in Birjand city. It could also highlight the role of the WSP in improving drinking-water quality and greatly assist in structuring decision-making in urban water supply systems by considering potential risks.

\section{Methods}

In this study, the WSP presented by the WHO and the IWA and the WSP-QA Tool were used to evaluate the safety of the water supply system in Birjand, Iran. The software can be used across a wide range of conditions from water suppliers who are at the beginning of WSP implementation to those who have used the WSP. When the tool is employed in the primary stages of WSP development, it functions as a guide and evaluates the manner of plan implementation. For data collection, software checklists consisting of 85 questions or 110 question items were prepared in the form of 12 tables by individual phases of the WSP implementation. To complete the questionnaires and record the information on these checklists, the background and information registered in an urban water and wastewater and regional water affairs company in Birjand and local observations were used. The obtained information and data were fed into the software both quantitatively and qualitatively. The answers to questions related to general information associated with water suppliers and general information associated with each water supply system was recorded quantitatively in the software. However, the answers required for the questions corresponding to wasp's executive steps were introduced into the software based on a scoring system in line with the instructions. In the 


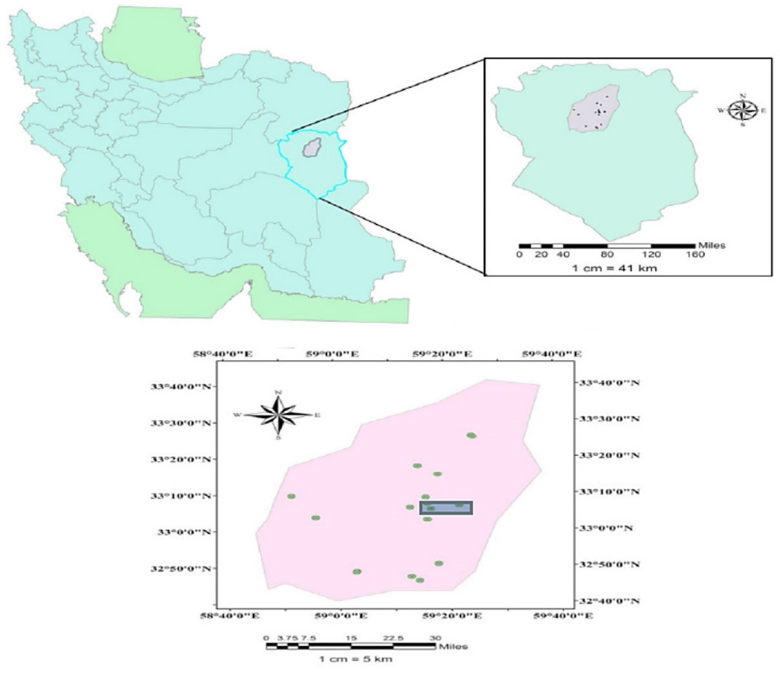

Figure 1. Geographical Position of the Studied Region (26).

system, scoring is based on the manner of implementation of every stage ranging from 0 to 4 , in which every stage can range from "not started" to "done completely." Furthermore, in addition to the mentioned scores, some questions could be marked "not applicable." The possible raw score, the score acquired in this investigation, and the extent of progression in implementation in terms of percentage for each phase were calculated based on predetermined and certain relations in the software. Following completion of the evaluation process, the results were presented in the form of graphs and tables which will help water suppliers in easily identifying sites in which attempts to improve the system, points of the system that require more resources for development, and regions in which progress has occurred should be targeted. Thus, the honesty in the responses of water suppliers as well as their critical evaluation regarding the developed advances are very important (1).

Measuring the validity of the translation of the software questions

In this study, to measure the validity of the translation of the software questions, the translation-back translation technique was employed. For this purpose, the English version of the software questionnaire was first translated into Persian by two experts in Persian and English and a specialist in environmental health engineering (translation stage). In the next stage, during a meeting with the research team, the two translated texts were compared with each other and evaluated in terms of quality. In some cases, to select the most suitable translation for statements, the initial translations were combined and composed in order to reach a consensus regarding a common Persian version. Then, the single, final translated version was given to two other translators who had not seen the initial English version to translate back into English from Persian (back translate stage). This was done to gain greater confidence in the accuracy of the questionnaire translation. In another meeting, the two versions translated into English were compared with each other in terms of quality and equalized. Finally, the two translations were changed into a single English version. With another meeting of the research team, the final English translation was compared with the original English text of the questionnaire, and conceptual equality (the consideration of original questionnaire conceptions) and the overall quality of the translation were examined. Eventually, following application of required changes and modifications according to the comments of translators and experts, the final Persian version was prepared based on the final translation of the questionnaire.

The stage of validation of the instrument

For scientific validation of questionnaires, scales, and checklists designed in routine ways, face validity and content validity methods are usually used along with an expert panel (28). Following preparation of the final version of the questionnaire used in this study, its scientific validity, face validity, and content validity were investigated using validation methods and an expert panel. In this study, the instrument designed by the research team was given to eight experts experienced in environmental health engineering. Based on the findings from the validation stage, the instrument was approved by all members of the expert panel in terms of correspondence of its content with valid and scientific texts. Some suggestions and modifying comments were given, and after investigation by the research team, the required changes and modifications were applied to the instrument; eventually, an instrument with an acceptable and approvable face and content validity was prepared.

Results

The following tables and diagrams present the results of evaluation of the extent of general implementation of WSP phases in this investigation, which can help water suppliers understand their general performance.

In Table 2, the options in the first column represent the stages of implementation and step-by-step development of a complete WSP, where the application and extent of progression of implementation of each stage according to WSP in the drinking water supply management system was evaluated through responses to the questions on the relevant checklists. After performing the required calculations using the software, the percentage of implementation corresponding with the WSP was calculated for each stage as an acquired score (\% implemented), which can be observed in the last column of the table.

In this investigation, the major components of a water supply system, i.e. resource, treatment, distribution, and final point of use, were also analyzed using the software. The results related to the percentage of implementation of 
Table 2. Results of general evaluation of WSP phases by WSP-QA Tool for drinking water supply system in Birjand city in 2015

\begin{tabular}{lccc}
\hline & Overall progress with WSPs in Birjand city & \\
\hline WSP implementation stages & No. of questions & Total possible point & Score (implemented \%) \\
\hline WSP team & 5 & 20 & $12 / 20(60.00 \%)$ \\
System description & 2 & 8 & $7 / 8(87.50 \%)$ \\
Hazard identification and risk assessment & 7 & 100 & $52 / 100(52.00 \%)$ \\
Control measures and validation & 5 & 68 & $44 / 68(64.71 \%)$ \\
Improvement plan & 3 & 48 & $-*$ \\
Operational monitoring & 4 & 64 & $43 / 64(67.19 \%)$ \\
Verification & 8 & 32 & $23 / 32(71.88 \%)$ \\
Management procedures & 3 & 36 & $9 / 36(25.00 \%)$ \\
Supporting programs & 2 & 8 & $-*$ \\
Review of the WSP & 5 & 56 & $-*$ \\
Total & 44 & 440 & $190 / 440(43.18 \%)$ \\
\hline
\end{tabular}

*The evaluation of this stage necessitates full implementation of WSP.

each evaluated parameter are presented as follows: Figure 2 indicates that, among the investigated phases, the processes associated with identification of stakeholders claimed the highest score, and the phase associated with management procedures and risk assessment had the lowest score in drinking water resources in Birjand city. Figure 3 demonstrates that in the water treatment plant, as with the results obtained for the resources, identification of stakeholders had the highest score, while risk detection and other examined processes had a $34 \%$ and $25 \%$ correspondence with the WSP, respectively.

Figure 4 suggests that among the phases examined across the water distribution system, in addition to identification of stakeholders, the phase related to operational monitoring also gained a high score (88\%). However, the process associated with risk assessment at this stage gained no score. Based on the results shown in Figure 5, it can be seen that at the point of use, as with the distribution system, the phase associated with risk assessment indicates the minimum percentage of congruent implementation with the WSP, while the processes related to operational monitoring reveal the maximum percentage of congruent implementation with the WSP. The results obtained from

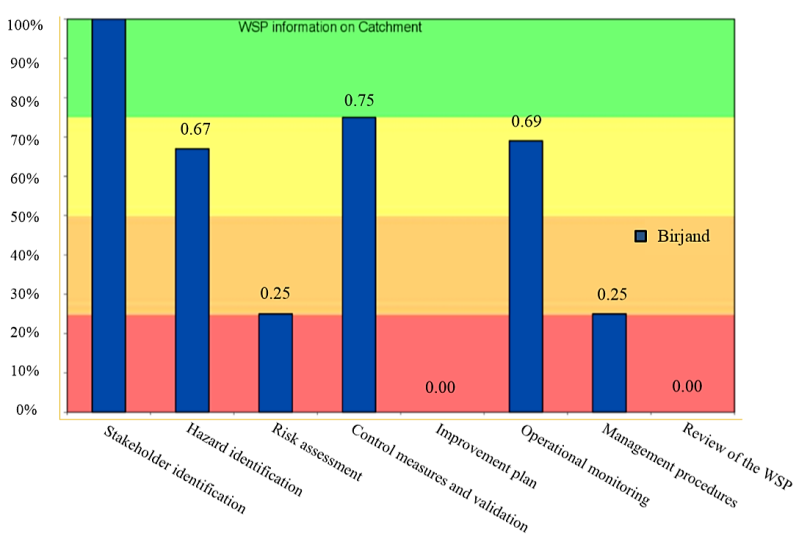

Figure 2. Results of WSP information for drinking water resources in Birjand City in 2015. diagrams indicated that application of the WSP-QA Tool as a support for WSPs has well highlighted the strong and weak points as well as the areas and opportunities requiring promotion in the major components of the water supply system in Birjand city.

In an investigation of the advances achieved through implementation of the WSP in Korea in 2013, identification

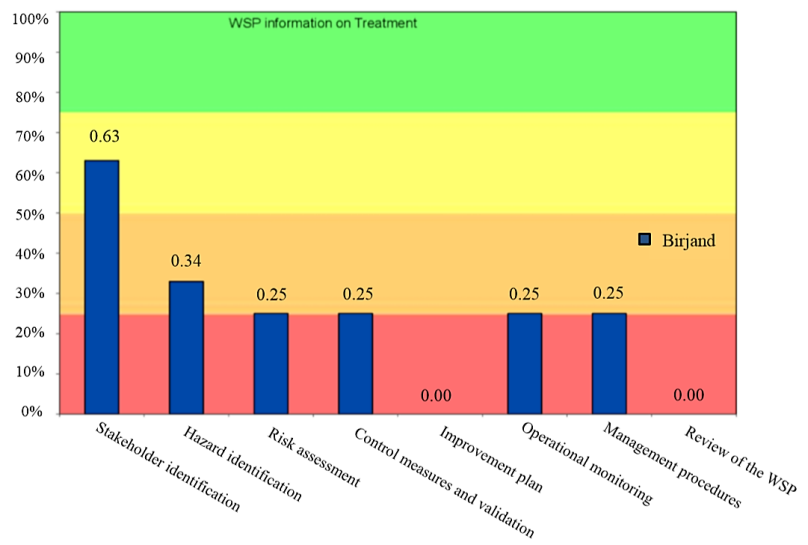

Figure 3. Results of WSP information for drinking water treatment plant in Birjand City in 2015.

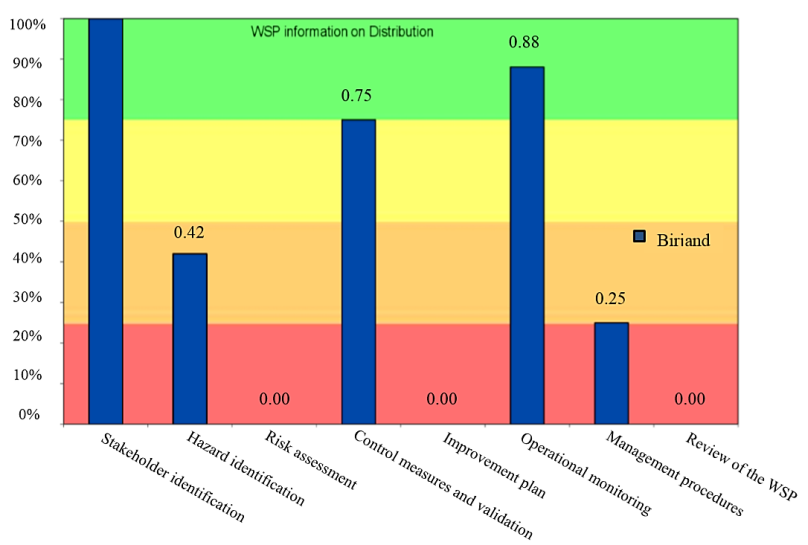

Figure 4. Results of WSP information for drinking water distribution system in Birjand city in 2015. 


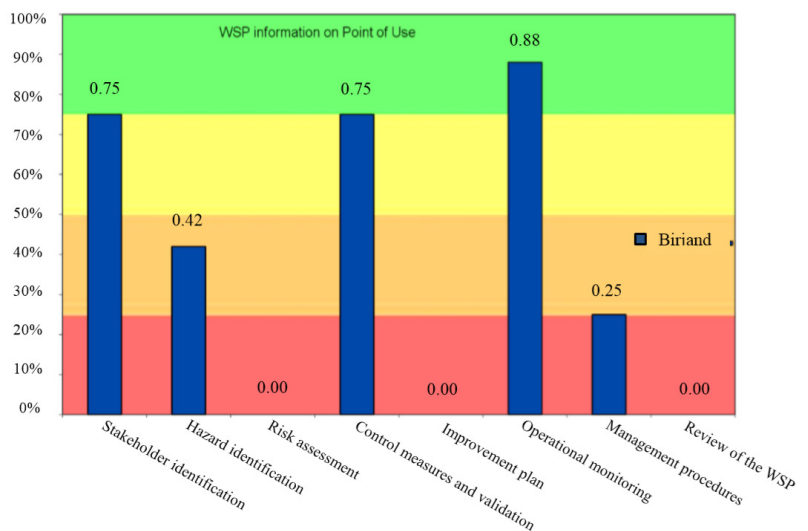

Figure 5. Results of WSP information for drinking water consumption point in Birjand city in 2015 .

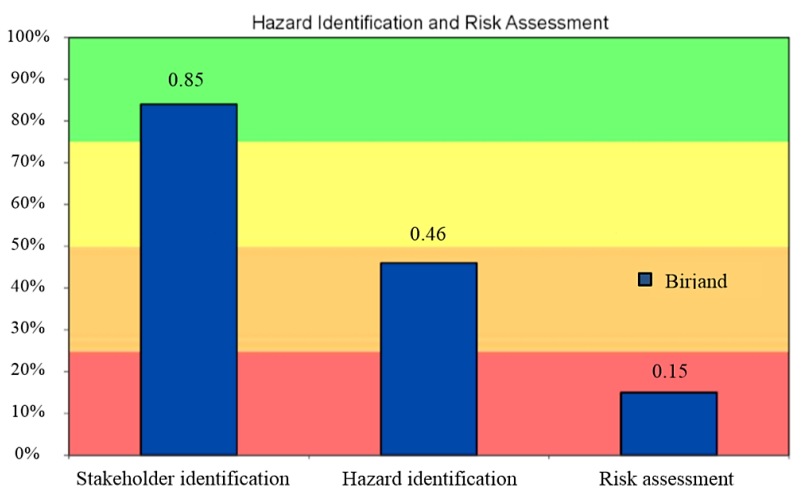

Figure 6. Extent of WSP implementation in the risk assessment and risk detection stage for the drinking water supply system in Birjand city in 2015.

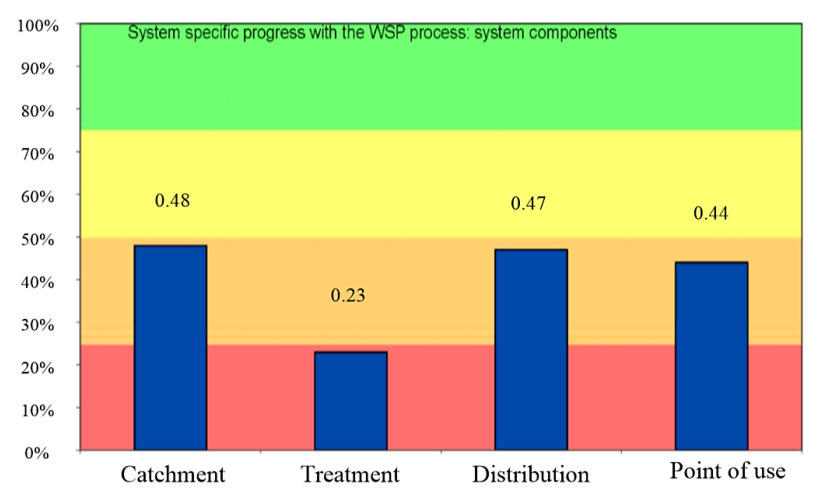

Figure 7. Extent of overall progression of implementation of WSP stages across major components of the drinking water supply system in Birjand city in 2015

and assessment of risk was defined as a key parameter in the WSP (29). This stage can be evaluated through the three parameters of identification of stakeholders, hazard identification, and risk assessment. In this investigation, according to Figure 6 and Table 2, this phase gained 52 out of 100 raw points, representing 52\% executive progression in line with the WSP. At this stage, the risk assessment parameter indicates the minimum percentage of implementation (15\%). According to Figure 7, the output results associated with the extent of progression of implementation of each WSP stage in terms of major components of the water supply system in Birjand indicated that among the major components of this system, water resources enjoyed the maximum attention, whereas the water treatment plant attracted the least attention of the water supplier system. A study which evaluated drinking water safety in Khoy city in 2010 found that the distribution system enjoyed the maximum attention of the water supplier organization (14).

\section{Discussion}

In this investigation, WSP-QA Tool along with the WSP manual presented by WHO and IWA were used to evaluate the stages of implementation of the WSP in the water supply system of Birjand city. The results shown in Table 2 indicate that from the 440 points for complete application of the plan and 328 points associated with the investigated phases, 190 points were obtained and a $43.18 \%$ congruence with WSP implementation was observed. The system description stage (7 out of the total 8 points) showed the maximum percentage of congruent implementation with the WSP $(87.5 \%)$, whereas the phase related to management procedures had the lowest score (9 out of the total 36 points) and claimed the minimum percentage of implementation $(25 \%)$. These results reveal that, although management procedures are an important part of the WSP, in the current approach, they are not of great interest to the company. These procedures include standard operating procedures (SOPs) and corrective activities (at the time of incident). Unexpected accidents and deviations in water supply systems may occur when there is no corrective activity at a certain site. Therefore, these procedures should be developed by experienced employees and updated and documented if necessary. In 2014, Aghaei evaluated the safety of the water supply system in Ardebil city and observed $21 \%$ congruent implementation with the WSP. In this study, the system description stage also claimed the maximum percentage of congruent implementation with the WSP, whereas the phase related to management procedures claimed the minimum percentage (10). These results are in line with those of the current research. The potential of the software is such that evaluation of some stages of implementation of the WSP (including WSP review, improvement plan, and supporting programs) necessitates complete implementation of the plan in water supply system management; as WSP was not implemented completely in Birjand city, the questions and scores related to phases that could not be evaluated were not included in the final analysis. This is also justifiable considering the feature of the software in independent analysis of the data of each phase. Evaluation of the application of the eight parameters mentioned in Figures 2 to 5 , which is somehow in line with corresponding 
phases in the WSP, for different components of water supply system (catchment, treatment, distribution, and point of use) indicated that the processes associated with the identification of stakeholders across different parts (resources, treatment plant, and distribution system) as well as the process related to operational monitoring at the final point of consumption gained the maximum score. It is notable that, although system description indicated the maximum percentage of congruent implementation with the WSP, the processes associated with risk assessment across all four parts of the water supply system (especially distribution system and the final point of use with a score of zero) were among the processes that gained the lowest scores. This suggests a lack of concentration of the water supplier system on the risk assessment process. The best way to achieve this target, according to the WSP manual, is to draw a simple table with the systematic registration of all hazardous events and relevant risks along with an estimation of their risk level. The risk assessment process can be based on a quantitative, semi quantitative (through a risk assessment matrix), or a simple qualitative solution (based on the judgment of the WSP expert panel). A WSP workshop in Berlin in 2014 also introduced this plan as an effective method for risk management in the 21 st century. It further stated that, even in cases of high correspondence with the drinking water directive of the European Union (EU-DWD), the WSP is a systematic method and suitable management instrument to ensure continuous delivery of healthy drinking water to consumers (21). In a study by Gholami et al on the water supply system in Khoy city, identification and risk assessment stage showed 12\% congruent implementation with the WSP (14). The results of the study by Aghaei on the water supply system in Ardebil city indicated that, considering the low percentage of general application of different WSP phases of and regarding the lack of attention to some key parameters including risk assessment and catchment management by the water supplier system, the current system does not enjoy the necessary safety, and the governing controlling approach does not have the efficiency required for integrated management of a healthy drinking water provision system (10). In this study, analysis of the results obtained from the diagrams revealed that, considering the percentage of general application of different WSP phases, the operational concentration of the supplier system is mainly on the verification stages and system description, such that the processes associated with risk assessment and management procedures gained a low score across all four main parts of the water supply system. Therefore, the major disadvantage of the current approach governing the qualitative management of drinking water in Birjand city, i.e. dependence on end-product experiments. This is in accordance with the results obtained by Gholami et al in their evaluation of drinking water safety in Khoy city (14). According to the report of progression of development of the WSP in Korea in 2013, the objectives in developing this plan is to protect and enhance the safety of drinking water as well as to identify and assess the risks and hazardous events in the water supply system. The report stated that the main characteristic of WSP implementation in this country is the presentation of a water safety index (WSI) to detect the safety level of drinking water and to identify the weak points in the water supply system. It is highly useful to gain a quick understanding of the water safety level in a water supply system and to detect the vulnerable points of the system (29). The most effective method for achieving sustainable confidence about the safety of a drinking water supply system is the application and management of a comprehensive risk assessment approach, such that it covers all the stages involved in water supply from catchment to the consumer. Such solutions are called WSP (30). The WSP quality assurance tool helps meet this need and also supports WSP teams in the development and implementation of the WSP (31).

\section{Conclusion}

Overall, the results indicate that the aims of using the WSP-QA Tool as a support for WSPs, i.e. the identification of the water supply system's weak points and evaluation of the percentage of implementation in line with each stage of the WSP in qualitative management of the drinking water in Birjand city, have been fulfilled completely. Not only did these results differentiate between areas and opportunities requiring promotion, but it also determined the inadequate efficiency of the traditional approach (relying on final point test), both of which were among the objectives of this study. Considering the percentage of the overall application of WSP phases and the low score of some key parameters such as risk assessment and management procedures, the system currently enjoys a relatively medium level of safety. However, considering the high scores of some phases, such as system description, operational monitoring, and validation, the greater attention given the parameters associated with hazard identification and risk assessment, and the application of proper management procedures which include evaluation of the system from catchment to consumer, control measures for determining risks, a plan for monitoring control measures, corrective measures if the monitoring results show deviation from critical limits in a critical control point, and communication and support plans including standard operational procedures in a documented way, make it possible to enhance the system's flexibility to change the current approach of qualitative management into the WSP, eventually increasing the drinking water safety level in the water distribution system. Drinking water should enjoy both a desirable chemical quality and a bacteriological quality. The special chemical and microbiological quality of groundwater resources for the water supply in Birjand city has caused the qualitative indices of the water to digress from desirable limits due to the geological structure of the 
region, high thickness of alluvial sediments on which the city is settled, and continual and progressive withdrawal from these resources because of population growth. The WHO guidelines recommend the WSP as the most effective tool for ensuring safety in a drinking water supply. As a powerful tool for the management of drinking water safety, the WSP presents a systematic approach to ensure the quality and safety of water distributed to consumers from catchment to consumption point. The aim of the WSP is to ensure the quality of drinking water based on risk management, which emphasizes the prevention from contamination of drinking water resources, water treatment for decreasing or removing contamination to achieve standards, prevention of water re-contamination during storage, distribution, and consumption. Considering the effects of the WSP on the quality of water from catchment to consumption, the implementation of this plan as the most effective tool for ensuring safety in the supply of drinking water is recommended to water supplier organizations.

\section{Acknowledgments}

This paper is adapted from part of the results of a thesis entitled "Assessment of Safety in Drinking Water Supply System of Birjand city by Using World Health Organization's WSP, Based on Risk Management Approach" and research plan No 6449 at the Health Faculty of Shahid Beheshti University of Medical Sciences.

\section{Ethical issues}

It is confirmed that this manuscript is the original work of the authors. It has not been published, nor is it under review in another journal, and it is not being submitted for publication elsewhere.

\section{Competing interests}

The authors confirm that there are no competing interests.

\section{Authors' contributions}

All authors of this study contributed equally and participated in the collection, analysis, and interpretation of the data and manuscript writing.

\section{References}

1. Bartram J, Corrales L, Davison A, Deere D, Drury D, Gordon B, et al. Water safety plan manual: step-by-step risk management for drinking-water suppliers. Geneva: World Health Organization; 2009.

2. World Health Organization. Guidelines For DrinkingWater Quality. 3rd ed. Geneva: WHO; 2004.

3. Hrudey SE, Hrudey EJ, Pollard SJ. Risk management for assuring safe drinking water. Environ Int 2006; 32(8): 94857. doi: 10.1016/j.envint.2006.06.004.

4. World Health Organization, UNICEF. Global Water Supply and Sanitation Assessment 2000 Report. Geneva, Switzerland: WHO; 2000.

5. Summerill C, Pollard SJ, Smith JA. The role of organizational culture and leadership in water safety plan implementation for improved risk management. Sci Total Environ 2010; 408(20): 4319-27. doi: 10.1016/j.scitotenv.2010.06.043.

6. Roozbahani A, Zahraie B, Tabesh M. Water Quantity and Quality Risk Assessment of Urban Water Supply Systems with Consideration of Uncertainties. Water and Wastewater 2013; 24(4): 2-14. [In Persian].

7. Nijhawan A, Jain P, Sargaonkar A, Labhasetwar PK. Implementation of water safety plan for a large-piped water supply system. Environ Monit Assess 2014; 186(9): 554760. doi: 10.1007/s10661-014-3802-x.

8. World Health Organization. Guidelines for drinkingwater quality. Vol. 2, Health criteria and other supporting information: addendum. 2nd ed. Geneva: WHO; 1998.

9. Gunnarsdottir MJ, Gardarsson SM, Elliott M, Sigmundsdottir G, Bartram J. Benefits of Water Safety Plans: Microbiology, Compliance, and Public Health. Environ Sci Technol 2012; 46(14): 7782-9. doi: 10.1021/es300372h.

10. Aghaei M. Assessment Of safety in Drinking Water Supply System of Ardabil City By Using World Health Organization's Water Safety Plan, Based On Risk Management Approach [dissertaion]. Tehran: Tehran University of Medical Sciences; 2014. [In Persian].

11. Sun F, Chen J, Tong Q, Zeng S. Integrated risk assessment and screening analysis of drinking water safety of a conventional water supply system. Water Sci Technol 2007; 56(6): 47-56. doi: 10.2166/wst.2007.583.

12. Yazdanbakhsh AR, Manshoori M, Nabizadeh R, Jahed GR, Fallahzade RA. Guidelines of Water Safety Plan Based on Hazard Analysis and Critical Control Points (HACCP) System.Tehran: Avay Ghalam; 2009. [In Persian].

13. Eslami A, Barikbin B, Ghaffari M, Fanaei F. Assessment of Water Safety Plan (WSP) Implementation and Risk Management in Sarayan City. Zanko Journal of Medical Sciences 2017; 18(57): 81-95.

14. Gholami M, Bodaghi S, Babaloo E. Assessment of water safety plan in Khoy city based on step by step risk management new approach. Proceedings of the 14th National Conference on environmental health; 2011; Yazd, Iran.

15. Omar YY, Parker A, Smith JA, Pollard SJ. Risk management for drinking water safety in low and middle income countries - cultural influences on water safety plan (WSP) implementation in urban water utilities. Sci Total Environ 2017; 576: 895-906. doi: 10.1016/j.scitotenv.2016.10.131.

16. World Health Organization. A road map to support country-level implementation of water safety plans. Genova: WHO; 2010.

17. Tavasolifar A, Bina B, Amin Mohammad M, Ebrahimi A, Jalali M. Designing hazard analysis and critical control point system in drinking water supply system of Isfahan, Iran from Resource to Endpoint. J Health Syst Res 2011; 7(6): 1102-13. [In Persian].

18. Oluwasanya GO, Carter RC. Water safety planning for small water supply systems: the framework and control measures. Water Science and Technology: Water Supply 2017; 17(6): 1524-33. doi: 10.2166/ws.2017.057.

19. Davison A, Howard G, Stevens M, Callan P, Fewtrell L, Deere D, et al. Water safety plans: managing drinkingwater quality from catchment to consumer. Geneva: World 
Health Organization; 2005.

20. World Health Organization. The report on the implementation of the water safety plan, In pilot models and in water utilities participating in WSP - Phase 1. Viet Nam: WHO; 2010.

21. World Health Organization, International Water Association. European Strategic Workshop on Water Safety Planning Berlin. Germany: Key Outcomes; 2014.

22. EEM. Water Safety Plan, Spanish Town Water Supply. St. Catherine. Jamaica: EEM; 2007.

23. World Health Organization, International Water Association. Water safety plan quality assurance tool. Geneva: WHO; 2013.

24. Hajipoor M, Moodi M, Sharafi H, Eshaghi Nasab M, Mehrani M. Capabilities, potentials and investment opportunities of South Khorasan. [cited 2017 Aug 2]. Available from: http://investin-khj.ir/ckfinder/userfiles/ images/Ebooks/farsi.pdf.

25. Introducing the city of Birjand. [cited 2016 Apr 16]; Avalable from: http://sk-shora.ir/index.php.

26. Khosravi R, Eslami H, Almodaresi SA, Heidari M, Fallahzadeh RA, Taghavi $M$, et al. Use of geographic information system and water quality index to assess groundwater quality for drinking purpose in Birjand City, Iran. Desalination and Water Treatment 2017; 67: 74-83. doi: $\quad 10.5004 /$ dwt.2017.20458.

27. Pourtaghi ZS, Pourghasemi HR. GIS-based groundwater spring potential assessment and mapping in the Birjand Township, southern Khorasan Province, Iran. Hydrogeology Journal 2014; 22(3): 643-62.

28. Ghaffari M, Niknami Sh, Kazemnejad A, Mirzae E, Ghofranipour F. Designing and validating 10 conceptual scales to prevent HIV among adolescents. Journal of Kermanshah University of Medical Sciences 2007; 11(1): 38-50. [In Persian].

29. Korea Water Resources Corporation. The Development of Water Safety Plans in Korea. Daejeon: K-Water; 2013.

30. Manshouri M, Shaghaghi G. Water Safety Plan Manual Step-by-step risk management For drinking-water suppliers. Tehran: Ministry of Health, Treatment and Medical Training; 2009. [In Persian].

31. Gholami M, Boodaghi S. Water Safety Plan Quality Assurance Tool (User Manual). Tehran: Institute for Environmental Research, Tehran University of Medical Science; 2013. [In Persian]. 